\title{
Relationships and Loneliness - an exploratory study
}

\author{
Priyal Soni ${ }^{1}$, Riddhi Shah ${ }^{2}$, Vrushti Shah ${ }^{3}$, Neha Dalal ${ }^{4}$ \\ ${ }^{1-3}$ TYBA Students, ${ }^{4}$ Assistant professor \\ Department of Psychology, L.S.Raheja College of Arts and Commerce, Mumbai \\ Corresponding author: Ms. Neha Dalal \\ Email-neha.dalal@1sraheja.org
}

\begin{abstract}
Background: Loneliness is a common problem in relationships. The purpose of the study was to find out if there is a relation between loneliness and people in romantic relationship.

Methods: Convenient sampling was used to collect data in the age range of 18 to 25 years. Data was collected from 111 people out of which 37 were in a romantic relationship, 37 had been in a romantic relationship at least once in their lives and 37 had never ever been in a romantic relationship. Tool used to measure loneliness was UCLA loneliness scale.

Results: The data was not significant. It was found that the degree of loneliness was lowest in people who were in a romantic relationship and highest in the people had never been in a romantic relationship when the survey was conducted.

Conclusion:The results show that the difference between the mean reported loneliness for 3 groups is not significant. That is being in relationship, or not being in relationship romantically has no significant impact on feelings of loneliness reported in young adults.
\end{abstract}

Keywords: Romantic relationships, Loneliness, Young adults.

(Paper received $-3^{\text {rd }}$ January 2018, Peer review completed $-10^{\text {th }}$ January 2018)

(Accepted $-15^{\text {th }}$ January 2018)

\section{INTRODUCTION}

Keep in mind that to avoid loneliness, many people need both a social circle and an intimate attachment; Having just one of two may still leave you feeling lonely. -Gretchen Rubin

Loneliness is the lack of network of social relationships. For example, peers and relatives, it is something we all relate to even if we choose to ignore it. we all are worried about our co-existence as communities, but it is also something we should worry about. When a person is in fix or difficult situations he might get negative thoughts and may feel lonely although it is short lived in certain people it may prolong in a few; at this stage a person requires external support. we need people around us for support to enable ourselves to exist [1]. Loneliness is an unwelcome of lack or loss of relationships. A person may have many contacts on social networking sites but only the close relationship that he has is related to loneliness [2]. One person is enough to enhance one's mood many people are not required for the same. People today see romantic relationship as a way of getting rid of loneliness that is any two people of opposite gender attracted towards each other sexually. Although we are surrounded with people we sometimes feel lonely.

\section{Types of loneliness}

Social loneliness: A person lacks the ability to take their stand in a social setting. Though these people are involved in many groups, they don't feel attached to it. [3] 
Emotional loneliness: The person lacks close relationships such as with a spouse, good friends, parents,etc. [3]

Existential or cosmic loneliness: This is an isolating loneliness experienced by a person who is facing death. [3]

\section{Theories of loneliness}

According to John Bowlby's attachment theory, children come into the world biologically pre-programed to form attachment with others because this will help them to survive. Then in 1980s this theory was applied to adult romantic relationships. Four styles of attachment have been identified in adults: secure, anxious-preoccupied, dismissive-avoidant and fearful-avoidant. These roughly correspond to infant classifications: secure, insecure-ambivalent, insecure-avoidant and disorganized/disoriented which have also been discussed by Cindy Hazan and Phillip Shaver in the 1980s.

Erik Erikson's theory of psychosocial development focused on social interaction with other people and it included 7 stages, one of which is intimacy versus isolation. This stage focuses on people in early adulthood. In this stage one begins to explore themselves more intimately and share that intimacy with others. Positive outcome includes development of loving, sexual relationships and close friendships and negative outcomes include fear of relationships with others.

\section{Loneliness and Health}

Persistent loneliness may have impact on our physical and mental health. For example, obesity, hypertension, depression, suicidal thoughts, alcoholism, etc. Since humans belong to the social species. They require human contact to survive in the society, which are important for a person's physical and mental well being, impairment of which could lead to the feelings of loneliness. It could lead to various psychiatric disorders like Alzheimer's disease, alcohol abuse, drug abuse etc. One of the main indicators of social isolation is loneliness. It is not caused by being alone, but by the fear of alone, but by the definite need of a relationship or a set of relationships. It was found that Loneliness was a common experience found in $80 \%$ of the population below 18 years of age and $40 \%$ of the population above 65 years of age, reported loneliness at least sometimes in their life.

\section{Statement of Problem}

This study was conducted to find out the relationship between people who were in a romantic relationship, people who were in a romantic relationship once in their lives and the people who have never been in a romantic relationship and the degree of loneliness.

There are several researches on social isolation and oldage and college students. There have been many researches on loneliness but did not come across any researches on loneliness with romantic relationships.

A study was conducted to find Effect of Loneliness on the Psychological Well-Being of College Students. So, data on 101 college students was collected who were divided into two groups i.e. Males and Females. They were required to fill a questionnaire through email that had Ryff's questionnaire of psychological well-being and UCLA loneliness scale.

The findings of the research done by Bhagchandani revealed that there is a significant negative relationship between loneliness and psychological well-being. Also, the difference between males and females regarding both loneliness and psychological well-being did not come out to be significant.

In another study it was seen that the changing family and social structures and increased individualisation may mean that loneliness and social isolation are increasing in the UK. Loneliness is characterised by negative feelings relating to the quality of an individual's social relationships while social isolation relates to the numbers and frequencies of social contacts of an individual. While both concepts' definitions are contested and can be difficult to measure, several reports attest to the fact that a significant minority of individuals is experiencing loneliness and/or social isolation in the UK at a given time. A large body of studies demonstrate how loneliness and social isolation can lead to a number of physical and mental health problems. High levels of loneliness are associated with depressive symptoms, deliberate self-harm and cognitive decline. Social isolation and loneliness are both associated with increased risk of premature 
mortality, elevated blood pressure, heart problems, declining physical functioning, physical disability, unhealthy behaviours and worse overall self-reported health. These problems pose a serious public health risk both for individuals and for society in terms of healthcare costs and loss of economic activity. Befriending is a service provided by volunteers who offer companionship on a regular basis for a range of socially isolated or lonely individuals. Unique benefits for befriendees include regular social contact from someone who is not being paid to spend time with them, the opportunity for a mutual and reciprocal friendship-like relationship and support in reengaging with their local community. Research on its effects is scarce but suggests befriending could have a positive effect on individual's health, and has the potential to be a cost-effective intervention. Befriending can also benefit the volunteer befrienders who are similarly able to reengage with their community, and may derive health benefits from regular volunteering. Befriending has the potential to be an important aspect of the overall approach to helping the most isolated and lonely individuals in our society. More research is needed to substantiate these findings.

\section{METHODOLOGY}

\section{Independent Variable}

1. People who are currently in a romantic relationship.

2. People who were in a romantic relationship in past.

3. People who were never in a romantic relationship.

\section{Dependent Variable}

Scores on UCLA loneliness scale. (Russell D.,1996)

\section{Hypothesis}

There is no difference between the scores of loneliness of the people who were in a romantic relationship, who have been in a romantic relationship atleast once in their lives and who had never been in a romantic relationship.

\section{Sampling procedure}

Convenient sampling was used to collect the data. The method used for collecting data was a social survey questionnaire. The questionnaire was circulated via social media to the youngsters between the age of 18 to 25. The statistical tool used was one-way ANOVA.

\section{Tools}

UCLA Loneliness Scale: It was developed at University of California, Los Angeles. It helps in the assessment of subjective feelings of loneliness or social isolation. The questions in UCLA were worded in a negative or "lonely" direction, with people indicating how often they felt on a four-point scale that ranged from "never" to "often". The revised version included 10 positive and negative items each. Recently, in the $3^{\text {rd }}$ version the wording and the response format has been simplified. UCLA Loneliness Scale is composed of 20 items, and participants rate their agreement from 1 (not at all true of me) to 4 (very true of me) on a 4-point Likert-type scale. It is a summative scale whereby all the scores are added to obtain one score. The higher the score is, the higher level of loneliness is. Cronbach's alpha coefficient is reported as ranging from 0.89 to 0.94 across samples and test-retest reliability is 0.73 and re-test correlation coefficient is .73 (Russell, 1996). The scale was adapted into Turkish by Demir. Demir has found that Cronbach Alpha internal consistency coefficient of the scale to be 0.96 and re-test correlation coefficient after five weeks was found to be 0.94 .

\section{RESULTS}

It was seen that the mean of people who were in a romantic relationship while the survey was conducted is the lowest which is 15.91 and the standard deviation was 11.77. Following which the mean of the second group that is people who have been in a romantic relationship at least once in their life was 18.70 and the standard deviation was 13.02. The mean of third group that is of people who have never been in a romantic relationship was the highest that is 19.59 and the standard deviation was 12.30 . The difference between the 3 means was not significant as the F-value of one-way ANOVA was 0.89 and $\mathrm{p}<0.413646$. 
Table 1 - Loneliness scores across all three groups

\begin{tabular}{|c|c|c|c|c|}
\hline \multirow{2}{*}{$\begin{array}{l}\text { Loneliness } \\
\text { Scores }\end{array}$} & $\begin{array}{c}\text { People } \\
\text { current } \\
\text { romantic } \\
\text { relationship }\end{array}$ & $\begin{array}{c}\text { People } \\
\text { romantic } \\
\text { relationship } \\
\text { past }\end{array}$ & $\begin{array}{c}\text { People } \\
\text { Never in a } \\
\text { romantic } \\
\text { relationship }\end{array}$ & total \\
\hline $\mathrm{N}$ & 37 & 37 & 37 & 111 \\
\hline Mean & 15.9819 & 18.7027 & 19.5946 & 18.0721 \\
\hline Std. Dev. & 11.7789 & 13.0253 & 12.3096 & 12.3691 \\
\hline
\end{tabular}

\section{DISCUSSION}

The results show that the difference between the mean reported loneliness for 3 groups is not significant. That is being in relationship, or not being in relationship romantically has no significant impact on feelings of loneliness reported in young adults. Although several studies have implicated romantic relationships as significant contributor to mental health of adolescence and young adults including less reported loneliness, the same is not found in this study. Lot of these studies are originating in cultures where dating is common and being in romantic relationship is a form of having higher social status. India however, is a collectivistic and orthodox society where, romantic relationships are frowned upon with emphasis on arranged marriages and many a times romantic relationships are kept secret [4] Similar study found that not being in romantic relationship leads to loneliness more for young adults in United states rather than Korea. Korean adolescence did not report significant increase in loneliness for the lack of romantic relationship. Hence it is possible that cultural differences exist in romantic relationship as being influencer in reported feelings of loneliness.

Another important factor that helps in buffering the feelings of loneliness is friendship closeness. Studies have shown that social ties experienced while in close friendships act as important source of social support whereby adults not only get support but also are able to disclose problems and stresses in romantic relationships. Also having higher number of close friendships have resulted in people having less psychological distress and other psychological problems. Friendship closeness has also been found to act as a moderator between romantic experiences and psychological distresses. [5]

Studies done on loneliness and perceived social support among single and partnered young adults [6]have shown that people who have not ever been in a romantic relationship or are currently not in a relationship according to our criteria have been found to have grater loneliness among family and romantically, and are also perceived to have lesser social support from significant partners. This study also showed gender differences among the group it was found that men showed higher social loneliness than did women, but no differences existed in the perceived romantic loneliness. In another Turkish study based on social support and diseases it was found that cancer patients experienced a relatively low degree of loneliness when they had social support from their friends and family as opposed to when they did not have some or any kind of social support. There was found to be a significantly negative correlation between loneliness and social support scores. In another study based on family relationships and loneliness, which investigated the Japanese older adult's feelings of loneliness, it was found that parents who lived with their children their relationships with children not living with them did not generally affect the levels of loneliness, but the lack of a marital partner living in the same house had found to have significant effects on the levels of perceived loneliness. Whereas on the other side, parents who did not have children living with them the functional and associated family relationship patterns were found to have a significant impact on the loneliness of the parents. It was also found that frequent face-to-face meetings and regular communication did not have high effects on the loneliness of the parents but telephonic conversations did not seem to have any significant impact on the loneliness of the parents. [7-8] 


\title{
REFERENCES
}

1. Meltzer H, Bebbington P, Dennis MS, Jenkins R, McManus S, Brugha TS. Feelings of loneliness among adults with mental disorder. Soc Psych Psychiatr Epidemiol 2013;48(1):5-13..

2. Cacioppo JT, Hawkley LC, Ernst JM, Burleson M, Berntson GG, Nouriani B, Spiegel D. Loneliness within a nomological net: An evolutionary perspective. J Res Personality 2006;40(6):1054-85.

3. Perlman D, Peplau LA. Toward a social psychology of loneliness. Personal Relat 1981;3:31-56.

4. Cacioppo JT, Patrick W. Loneliness: Human nature and the need for social connection. WW Norton \& Company; 2008.

5. Hawkley LC, Cacioppo JT. Loneliness matters: a theoretical and empirical review of consequences and mechanisms. Ann Behav Med 2010;40(2):218-27.

6. Luo Y, Hawkley LC, Waite LJ, Cacioppo JT. Loneliness, health, and mortality in old age: A national longitudinal study. Soc Sci Med 2012;74(6):907-14.

7. Chow CM, Ruhl H, Buhrmester D. Romantic relationships and psychological distress among adolescents: Moderating role of friendship closeness. Int J Soc Psychiatry 2015;61(7):711-20.

8. Masi CM, Chen HY, Hawkley LC, Cacioppo JT. A meta-analysis of interventions to reduce loneliness. Personal Soc Psychol Rev 2011;15(3):219-66.

\author{
$* * * * * * * * * * * * * * * * * * * * * * * * * *$ \\ Acknowledgements - Nil \\ Conflict of Interest - Nil \\ Funding - Nil
}

